Perceptual and Motor Skills, 1992, 74, 403-411 C Perceptual and Motor Skills 1992

\title{
EFFECT OF PRIME AND TARGET REPETITION ON LEXICAL DECISION TIME ${ }^{1}$
}

\author{
ALFONSO PITARQUE, SALVADOR ALGARABEL, AND MARIA JOSÉ SOLER \\ University of Valencia, Spain
}

\begin{abstract}
Summary.-On a prime-target lexical decision task we manipulated the relatedness between prime and target (semantically related or unrelated), the number of repetitions (from 1 to 5), the type of the repeated stimulus (only the prime, only the target, or both), and the stimulus onset asynchrony (within a range of automatic activation from 60 to $400 \mathrm{msec}$.) to find whether semantic and repetition priming are additive (or interact), and whether there is episodic priming in an automatic, nonconscious way. Analysis showed repetition and semantic priming were additive rather than interactive. No episodic automatic priming was found. Results are discussed in terms of the predictions made from the main theoretical positions abour the repetition effect.
\end{abstract}

In chronometric experiments the repetition effect or repetition priming refers to the fact that the presentation of a single word is capable of significantly enhancing the fluency with which that word is identified on a second presentation. This word repetition effect has been demonstrated using a number of procedures including, for example, lexical decision (Forbach, Stanners, \& Hochhaus, 1974), word naming (Scarborough, Cortese, \& Scarborough, 1977), perceptual identification (Jacoby \& Dallas, 1981), recognition tasks (Ratcliff, Hockley, \& McKoon, 1985) and can be observed when repetition is made seconds, minutes, hours, or days apart (Feustel, Shiffrin, \& Salasoo, 1983; Salasoo, Shiffrin, \& Feustel, 1985; Scarborough, et al., 1977), or even when subjects are not aware of the first presentation of the stimulus (Forster, Booker, Schacter, \& Davis, 1990). Two broad theoretical accounts are given to explain such repetition priming phenomena: we will refer to them as lexical or semantic account and the episodic memory interpretation (see, for example, Forster, et al., 1990; Masson \& Freedman, 1990; Rueckl, 1990; Woltz, 1990).

The former theoretical account of the word repetition effect is based on the assumption that presentation of a word is capable of inducing the activation of its lexical representation. In word detector models (see, for example, Morton, 1979) faster performance on repeated trials is attributed to residual activation or lower thresholds of existing lexical or semantic memory codes for stimulus words. In lexical search models (see, for example, Forster, 1979) retrieval occurs through processes in which the input is compared sequen-

${ }^{1}$ This research was supported by Grant No. PB88-0496 from Promoción General del Conocimiento de la Dirección General de Investigación Cientifica y Técnica del M.E.C. Address correspondence to Dr. Alfonso Pitarque, Universitat de València, Facultat de Psicología, Avda. Blasco Ibañez 21, 46010 Valencia, Spain. 
tially with a set of representations of the candidate (ordered by the frequency of the concepts) until an adequate match is found. As repetition affects the frequency of the words, more repetitions mean a higher frequency and then a faster match.

An alternative view to the semantic account is that enhanced fluency through repetition is produced partly (Feustel, et al., 1983; Salasoo, et al., 1985) or completely (Jacoby, 1983) as a result of a newly created episodic representation of a word's occurrence. According to the episodic view, feature encoding operations from prior processing episodes facilitate subsequent encoding of the same stimuli. So, the repetition effect is somehow produced by the retrieval of the episodic memory trace created by the first processing of a word.

Both semantic and episodic views have experimental evidence about the repetition effect that seems to refute (or to support) their postulates. For example, lexical views can account for facts as a semantic priming effect (Meyer \& Schvaneveldt, 1971), why amnesics show repetition effects despite their not being aware of episodic events related to the former experiences (see Schacter, 1987) or why changing the alphabet across two bilingual presentations of a word did not influence the repetition effect (Feldman \& Moskovljevic, 1987). These results are consistent with an account that includes the sustained activation of the lexical referent of a visual pattern.

Some of the basic assumptions of the lexical view, however, have been questioned. The most provocative finding is why on lexical decision and naming tasks semantic and repetition priming seem to be additive rather than interactive, as would be expected if both procedures involve activation of some lexical structure (see Algarabel, Pitarque, \& Soler, 1988; den Heyer, Goting, \& Dannenbring, 1985). The facts that the repetition effect is found in pseudowords (Salasoo, et al., 1985), lasts much longer than expected (Scarborough, et al., 1977), or is associated with different patterns of event-related potentials according to its semantic or episodic nature (Rugg, 1987) pose some additional problems for the lexical view.

Such results led many investigators to reject the lexical account and to propose instead that repetition priming is somehow produced by the retrieval of the episodic memory trace of the first encounter. Recruitment does not always take the form of conscious recollection of episodes but may also occur automatically and without awareness, or in Schacter's terminology "implicitly" (see Forster, et al., 1990; Masson \& Freedman, 1990).

The general purpose of our experiment was to measure the effects of repetition on activation of the semantic traces as a way of deducing the general properties of how information is recovered from memory. Thus, on a prime-target lexical-decision task we presented repeatedly along five blocks of trials (see also, Higgins, Bargh, \& Lombardi, 1985) the prime stimulus, the 
target stimulus, or both on the assumption that presentation of a word (either prime, target, or both) activates its semantic representation as well as the trace which connects prime and target. The decrease in latencies which we would expect with practice would be explained by lexical models as effects of the increase in the detection thresholds of existing lexical or semantic memory codes. By contrast, episodic views would state that not only thresholds but also episodic traces would be strengthened.

More specifically, we were interested in finding an answer to the question of whether the priming effect grows as a result of practice. That is to say, do semantic and repetition priming interact as lexical models would predict? This is an important theoretical point because some authors (see den Heyer, 1986) have stated that the two processes rely on different processing stages. A significant interaction would show, by contrast, that only one mechanism might explain such results. One way to test this idea might be to compare the condition wherein the target is a word related to the prime and repeated versus a condition in which the target is nonrelated and repeated. According to lexical models, in the former condition the average latencies would reflect the effect of the prime activation over the target as well as the effect of the repetition of the target per se. If the stimulus-onset asynchrony is of short duration, then an additive effect between repetition and semantic priming would support the lexical view. On the contrary, an interaction between them would support the episodic view.

We manipulated three variables in a lexical decision task: the number of repetitions manipulated (five blocks of presentations), the type of repeated item (repeating the prime, the target, or both), and the stimulus-onset asynchrony within a short range: $40,60,100,200,300$, and 400 milliseconds.

\section{METHOD}

\section{Subjects}

One hundred and twenty undergraduate students of psychology (24 men and 96 women) were chosen from the University of Valencia (Spain) as experimental subjects, receiving academic credit for their participation. All were native speakers of Spanish, had normal or corrected-to-normal vision, and were in the range 19 to 35 years (mean: $22.2 \mathrm{yr}$.).

\section{Stimuli}

The stimuli were 350 stimulus pairs selected from Spanish category norms (Pascual, Gotor, Miralles, \& Algarabel, 1979). These category norms are equivalent to Battig and Montague's (1969), and they were obtained using a similar procedure. One list was formed from 390 distinct words, randomly chosen with the restriction that they were represented in the norms with a frequency of at least nine responses for a sample of subjects. 
The 350 trials which composed a session were divided in five blocks of 70 trials with 35 pseudoword and 35 word target trials per block. In the whole experiment there were 175 word target and 175 pseudoword target trials.

When the target was a word, there were seven different conditions: (1) a prime related to the target and not repeated throughout the five blocks (as in vest-clothes, hammer-tool, brown-color, oak-tree, apple-fruit), (2) a prime related to the target and repeated (as in coin-peseta, coin-dollar, coin-pound, coin-lire, coin-franc), (3) a target related to the prime and repeated (as in chemistry-science, biology-science, psychology-science, medicine-science, physics-science), (4) a target unrelated to the prime and repeated (as in windowfamily, mountain-family, soldier-family, door-family, leg-family), (5) a prime and target related and repeated (as in drink-wine, drink-wine, drink-wine, drink-wine, drink-wine), (6) a prime and a target unrelated and repeated (as in animal-bishop, animal-bishop, animal-bishop, animal-bishop, animal-bishop), and (7) the prime "NEUTRO" ("neutral") and repeated, as the control condition (as in neutral-tennis, neutral-trout, neutral-boxing, neutral-valley, neutral-Italy).

When the target was a pseudoword, the conditions were (8) a word prime repeated (as in paper-wune, paper-bushop, paper-cer, paper-fiald, paperhaur), (9) a target repeated (as in knife-gliss, screw-gliss, axe-gliss, curtaingliss, rain-gliss), (10) a prime and a target repeated (as in oak-wull, oak-wull, oak-wull, oak-wull, oak-wull), (11) a prime and a target nonrepeated (as in week-wendow, sun-peth, lamp-rocord, saucer-teapet, broom-jeg), and (12) the prime "NEUTRO" repeated (as in neutral-pellow, neutral-merror, neutralsoep, neutral-fermer, neutral-dem).

\section{Procedure}

The procedure involved the presentation of five blocks of 70 trials, containing the conditions specified above. When the target was a word, there were five representatives of each condition within a block, and seven when that target was a pseudoword. All individual trials consisted of the following sequence of events shown on the screen of an Apple Ile computer. First a warning signal, consisting of the "plus" sign centered in the monitor screen. After 500 milliseconds delay, the prime was presented, replacing the fixation stimulus, and was visible for $40,60,100,200,300$, or 400 milliseconds according to SOA condition with an interstimulus interval of 0 milliseconds. Finally the target replaced the prime and stayed on the screen until the subject typed the computer keyboard. The computer randomized a different sequence of stimuli for each subject within each block, registered reaction time, and provided feedback on accuracy of response. The instructions given to the subjects put an emphasis on speed and accuracy. 


\section{Results and Discussion}

Errors were $3.33 \%$ of all responses. Given their relative insignificance no attempt was made to analyze them. All individual latencies above or below the mean (plus or minus 2 standard deviations) were eliminated from the analysis. With this criterion $4.39 \%$ of the responses were eliminated. Table 1 presents the mean reaction times by conditions for the valid target words.

TABLE 1

Mean Reaction Time for Word Target Conditions of Experiment

\begin{tabular}{|c|c|c|c|c|c|c|}
\hline \multirow[t]{2}{*}{ Block/Conditions } & \multicolumn{6}{|c|}{ Asynchrony (msec.) } \\
\hline & 40 & 60 & 100 & 200 & 300 & 400 \\
\hline \multicolumn{7}{|l|}{ Block 1} \\
\hline PR-R* & 694 & 676 & 682 & 642 & 634 & 619 \\
\hline PR-NR & 643 & 679 & 691 & 641 & 639 & 630 \\
\hline TR-R & 646 & 626 & 609 & 584 & 587 & 571 \\
\hline TU-R & 627 & 646 & 638 & 600 & 625 & 604 \\
\hline PTR-R & 620 & 620 & 621 & 617 & 593 & 580 \\
\hline PTU-R & 648 & 672 & 668 & 633 & 661 & 637 \\
\hline Control & 618 & 640 & 629 & 614 & 620 & 636 \\
\hline \multicolumn{7}{|l|}{ Block 2} \\
\hline PR-R & 663 & 698 & 679 & 612 & 638 & 623 \\
\hline PR-NR & 644 & 679 & 675 & 656 & 669 & 662 \\
\hline TR-R & 558 & 592 & 587 & 557 & 554 & 558 \\
\hline TU-R & 605 & 617 & 616 & 592 & 609 & 611 \\
\hline PTR-R & 580 & 584 & 600 & 537 & 534 & 555 \\
\hline PTU-R & 585 & 598 & 610 & 576 & 611 & 611 \\
\hline Control & 656 & 682 & 708 & 689 & 686 & 685 \\
\hline \multicolumn{7}{|l|}{ Block 3} \\
\hline PR-R & 714 & 692 & 713 & 659 & 633 & 642 \\
\hline PR-NR & 687 & 687 & 716 & 694 & 690 & 696 \\
\hline TR-R & 568 & 570 & 617 & 571 & 558 & 582 \\
\hline TU.R & 586 & 598 & 636 & 611 & 603 & 610 \\
\hline PTR-R & 571 & 565 & 601 & 540 & 535 & 542 \\
\hline PTU-R & 589 & 593 & 633 & 591 & 599 & 598 \\
\hline Control & 717 & 734 & 776 & 704 & 707 & 707 \\
\hline \multicolumn{7}{|l|}{ Block 4} \\
\hline PR-R & 654 & 662 & 663 & 612 & 599 & 599 \\
\hline PR-NR & 726 & 746 & 751 & 708 & 700 & 730 \\
\hline TR-R & 553 & 570 & 587 & 541 & 534 & 534 \\
\hline TU-R & 570 & 583 & 599 & 584 & 573 & 571 \\
\hline PTR-R & 563 & 569 & 582 & 542 & 523 & 515 \\
\hline PTU-R & 581 & 594 & 596 & 560 & 566 & 612 \\
\hline Contral & 670 & 686 & 735 & 669 & 674 & 665 \\
\hline \multicolumn{7}{|l|}{ Block 5} \\
\hline PR-R & 681 & 695 & 689 & 640 & 645 & 635 \\
\hline \multicolumn{7}{|c|}{ (continued on next page) } \\
\hline
\end{tabular}

*PR-R = prime related to the target and repeated; PR-NR = prime related and nonrepeated; TR-R = tirget related and repeated; TU.R $=$ target unrelated and repeated; PTR-R $=$ prime and target related and repeated; PTU-R = prime and target unrelated and repeated. 
TABLE 1 (CONT'D)

Mean Reaction Time For Word Target Conditions of Experiment

\begin{tabular}{lcccccc}
\hline \hline Block/Conditions & \multicolumn{7}{c}{ Asynchrony (msec.) } \\
\cline { 2 - 7 } & 40 & 60 & 100 & 200 & 300 & 400 \\
\hline PR-NR & 678 & 700 & 714 & 689 & 673 & 718 \\
TR-R & 568 & 566 & 584 & 551 & 530 & 560 \\
TU-R & 564 & 576 & 597 & 592 & 567 & 573 \\
PTR-R & 556 & 564 & 578 & 531 & 526 & 513 \\
PTU-R & 558 & 578 & 607 & 566 & 567 & 576 \\
Control & 692 & 681 & 728 & 692 & 685 & 711 \\
\hline
\end{tabular}

${ }^{\star} \mathrm{PR}-\mathrm{R}=$ prime related to the target and repeated; PR-NR = prime related and nonrepeated; $T R-R=$ target related and repeated; TU-R = target unrelated and repeated; PTR-R = prime and target related and repeated; PTU-R = prime and target unrelated and repeated.

Words and pseudowords were analyzed separately. The word analysis was carried out in two stages. Firstly, we analyzed classical priming effects and the effect of prime repetition. Secondly, we analyzed the effect of target and of prime and target repetition.

With respect to the first aspect, we submitted the mean reaction times to a mixed $6 \times 3 \times 5$ analysis of variance (asynchrony $\times$ relatedness condition $\times$ number of repetitions) in which the last two variables were within subjects. Blocks $(F=28.49, p<.001, M S e=5054.28)$ and relatedness conditions $(F=52.42, p<.001, M S e=3235.99)$ were both significant. Interactions of relatedness by asynchrony $(F=7.12, p<.001, M S e=3235.99)$ and relatedness by blocks $(F=19.57, p<.001, M S e=3657.81)$ were also significant. No other effect or interaction achieved statistical significance. To clarify further the meaning of the two obtained interactions, we decided to carry out an analysis of simple effects. The effect of relatedness was significant in stimulus-onset asynchronies ranging from 100 to 400 milliseconds $(p<.001)$ but not at 40 and 60 . Important also was the marginally significant effect of stimulus-onset asynchrony in repeated related prime condition $(p<.07)$, which showed a decrease in reaction time with increasing stimulus-onset asynchrony. Simple effects of block by relatedness showed significant effect of each variable at the level of the other $(p<.001)$. Newman-Keuls tests showed that, except for Block 1 wherein the control condition was the fastest in relation to the unrelated and related conditions, the related one was the fastest condition in the subsequent four blocks. These first series of analyses show a clear semantic priming effect. Semantic priming could also be observed when comparing related versus unrelated conditions in the analysis of a repeated target. Again, a related target was faster than an unrelated one (573 versus $599 \mathrm{msec}$.) and a related prime-target was faster than an unrelated prime-target ( 565 versus $603 \mathrm{msec}$.). This priming effect was dependent on stimulus-onset asynchrony. The analysis of simple effects for the control condition yielded a significant priming effect from $100-\mathrm{msec}$. stimu- 
lus-onset asynchrony onwards, while the analysis carried out on the condition of a repeated target showed an effect from 60 -msec. stimulus-onset asynchrony. Therefore, for this study the priming threshold is placed around 60 milliseconds, extending the function recently obtained in a parametric study (de Groot, Thomassen, \& Hudson, 1986; see also Neely, 1977), although the fact that priming could not be obtained at $40 \mathrm{msec}$. does not support claims made about unconsciousness priming (e.g., Balota, 1983).

Mean reaction times for word repeated targets were submitted to a mixed $6 \times 4 \times 5$ analysis of variance (asynchrony $\times$ relatedness condition $\times$ blocks), in which the last two variables were within subjects. Blocks $(F=55.38$, $p<.001, M S e=4653.74)$ and conditions of relatedness $(F=53.73, p<.001$, $M S e=3948.03)$ were both significant. Interactions of relatedness by asynchrony $(F=2.46, p<.001, M S e=3948.03)$ and relatedness by blocks $(F=$ $4.62, p<.001, M S e=1709.50$ ) were also significant. No other effect or interaction achieved statistical significance. Analysis of simple effects showed that conditions of relatedness were different at all levels except for the 40-msec. stimulus-onset asynchrony. The main interest of this experiment is centered on the possibility of obtaining a significant interaction between blocks and the amount of semantic facilitation for the conditions wherein the prime and target were repeated and when only the target was repeated on its own. To observe clearly this possible interaction we carried out two separate analyses of variance. The first one was carried out by taking blocks (5), asynchrony (6), and relatedness condition (2: target-related versus unrelated) as experimental factors. This analysis showed a significant interaction between blocks by condition $(F=2.99, p<.05, M S e=1622.88)$. Analysis of simple effects showed conditions differed across the five blocks $(p<.01)$. This difference increases up to Block 2, where it was especially greater, and subsequently fell to Block 5. While this interaction was significant, it was in the opposite direction that lexical models predict, namely, a decreasing and not increasing difference along blocks.

The second analysis was carried out with the same factors as the first one, but this time on the related versus unrelated prime-target conditions, both of which were repeated. The interaction of block by conditions was not significant $(F=1.15, p<.35, M S e=1760.17)$. In fact, both lines were completely parallel; no automatic episodic priming was found.

Data for pseudoword repeated target were submitted to a mixed $6 \times$ $5 \times 2$ analysis of variance (stimulus-onset asynchrony $\times$ block of repetitions $\times$ relatedness conditions), in which the last two factors were within subjects. Both blocks $(F=27.38, p<.001, M S e=3703.50)$ and the relatedness condition $(F=27.19, p<.001, M S e=2563.71)$ were significant. The interaction of repetitions by relatedness condition $(F=5.74, p<.001, M S e=1703.18)$ was also significant, but, as above, it was not in the direction that the episodic 
models predict. Also, a clear effect for pseudoword repetition was noted, a difficult result for lexical models to explain.

In short, our data, which show the classic effects of priming and repetition, seem clearly to refute the lexical models' predictions, given that we have not found the interaction between semantic and repetition priming in the expected direction (see Algarabel, Pitarque, \& Soler, 1988; den Heyer, Goring, \& Dannenbring, 1985), as well as a repetition effect with pseudowords.

On the other hand, the automatic episodic priming, that is, the interaction between related and unrelated conditions across repetitions, did not appear (see also den Heyer, 1986; den Heyer, et al., 1985). Perhaps the increasing amount of priming found with practice in conditions with unrelated and repeated targets compared with neutral conditions could be due more to the repetition target effect per se than to the strengthening of episodic traces by practice.

\section{REFERENCES}

Algarabel, S., Pitarque, A., \& Soler, M. J. (1988) Additivity from multiple primes in identifying backward written words. Perceptual and Motor Skills, 66, 715-721.

BALOTA, D. A. (1983) Automatic semantic activation and episodic memory encoding. Journal of Verbal Learning and Verbal Behavior, 22, 88-104.

BatTtG, W. F., \& Montague, W. E. (1969) Category norms for verbal items in 56 categories: a replication and extension of the Connecticut category norms. Journal of Experimental Psychology Monograph, 80 (3, Pt. 2).

de Groot, A. M. B., Thomassen, A. J. W. M., \& Hudson, P. J. W. (1986) Primed-lexical decision: the effects of varying the stimulus-onset asynchrony of prime and target. Acta Psychologica, 61, 17-36.

DEN HeyER, K. (1986) Manipulating attention-induced priming in a lexical decision task by means of repeated prime-target presentations. Journal of Memory and Language, 25, 19 42.

Den Heyer, K., Goring, A., \& Dannenbring, G. L. (1985) Semantic priming and word repetition: the two effects are additive. Journal of Memory and Language, 24, 699-716.

Feldman, L. B., \& Moskovljevich, J. (1987) Repetition priming is not purely episodic in origin. Journal of Experimental Psychology: Learning, Memory and Cognition, 13, 573-581.

Feustel, T. L., Shiffrin, R. M., \& Salasso, A. (1983) Episodic and lexical contributions to the repetition effect in word identification. Journal of Experimental Psychology: General, $112,309-346$.

Forbach, G. B., Stanners, R. F., \& Hochhaus, L. (1984) Repetition and practice effects in a lexical decision task. Memory and Cognition, 2, 337-339.

FORSTER, K. I. (1979) Levels of processing and the structure of the language processor. In W. E. Cooper \& E. C. T. Walker (Eds.), Sentence processing: psycholinguistics studies presented to Merrill Garrett. Hillsdale, NJ: Erlbaum. Pp. 27-85.

Forster, K. I., Booker, J., SClacter, D. L., \& Davis, C. (1990) Masked repetition priming: lexical activation or novel memory trace? Bulletin of the Psycbonomic Society, 28, 341345.

Higgins, E. T., Bargh, J. A., \& Lombard, W. (1985) Nature of priming effects on categorization. Journal of Experimental Psychology: Learning, Memory E Cognition, 11, 59-69.

JACOBY, L. L. (1983) Remembering the data: analyzing interactive processes in reading. Journal of Verbal Learning and Verbal Behavior, 22, 485-508.

JacoBy, L. L., \& Dallas, M. (1981) On the relationship between autobiographical memory and perceptual learning. Journal of Experimental Psychology: General, 110, 306-340. 
Masson, M. E. J., \& Frefdman, L. (1990) Fluent identification of repeated words. Journal of Experimental Psychology: Learning, Memory and Cognition, 16, 355-373.

MeYer, D. E., \& SChvnneveldt, R. W. (1971) Facilitation in recognizing pairs of words: evidence of a dependence between retrieval operations. Journal of Experimental Psychology, 90, 227-234.

Morton, J. (1979) Facilitation in word recognition: experiments causing change in the logogen model. In P. A. Kolers, M. E. Wrolstad, \& H. Bouma (Eds.), Processing of visible lenguage: I. New York: Plenum. Pp. 259-268.

NeELY, J. H. (1977) Semantic priming and retrieval from lexical memory: roles of inhibitionless spreading activation and limited-capacity attention. Journal of Experimental Psychology: General, 106, 226-254.

Pascual, J., Gotor, A., Miralles, J. L., \& Algarabel, S. (1979) Notmas categoriales para el estudio de la memoria humana. Actas del Congreso Nacional de Psicologia. Pamplona: The Congress. P. 74.

RATClifF, R., HockLEy, W., \& McKoon, G. (1985) Components of activation: repetition and priming effects in lexical decision and recognition. Journal of Experimental Psychology: General, 114, 435-450.

RUECKL, J. G. (1990) Similarity effects in word and pseudowords repetition priming. Journal of Experimental Psychology: Learning, Memory and Cognition, 16, 374.391.

RugG, M. D. (1987) Dissociation of semantic priming, word and nonword repetition effects by event-related potentials. Quarterly Journal of Experimental Psychology, 39A, 123-148.

Salasoo, A., Shifrrin, R. M., \& Feustel, T. C. (1985) Building permanent memory codes: codification and repetition effects in word identification. Journal of Experimental Psychology: General, 114, 50-77.

Scarborough, D. L., Cortese, C., \& Scarborough, H. (1977) Frequency and repetition effects in lexical memory. Journal of Experimental Psychology: Human Perception \& Performance, 3, 1-17.

SCHACTER, D. L. (1987) Implicit memory: history and current status. Journal of Experimental Psychology: Learning, Memory and Cognition, 13, 501-518.

WotTz, D. J. (1990) Repetition of semantic comparisons: temporary and persistent priming effects. Journal of Experimental Psychology: Learning, Memory and Cognition, 16, 392-406.

Accepted February 6, 1992. 
This article has been cited by:

1. Sandrine Perraudin, Pierre Mounoud. 2009. Contribution of the priming paradigm to the understanding of the conceptual developmental shift from 5 to 9 years of age. Developmental Science 12, 956-977. [CrossRef] 